\title{
Association of Blood Cholinesterase with Sexual Differences in Metabolic Health Risks among Villagers from Pesticide-Treated Farming Villages
}

\author{
Vivien How ${ }^{1 *}$, Shyamli Singh², Dang Quang Thinh"3 , How Ran Guo4, \\ Raihanah Chokeli ${ }^{5}$ and Nurul Syazani Yuswir ${ }^{5}$ \\ 'Senior Lecturer, Department of Environmental and Occupational Health, Universiti Putra Malaysia, \\ Selangor -43400, Malaysia; vivien@upm.edu.my \\ ${ }^{2}$ Assistant Professor, Centre for Environment and Climate Change, Indian Institute of Public Administration, \\ New Delhi - 110002, Delhi, India; shyamli.env@gmail.com \\ ${ }^{3}$ Viet Nam Institute of Meteorology, Hydrology and Climate Change, Ministry of Natural Resources and Environment, \\ Vietnam; thinhdangq@gmail.com \\ 4Professor, Department of Environmental and Occupational Health, National Cheng Kung University, \\ Tainan City - 701, Taiwan; hrguo@mail.ncku.edu.tw \\ ${ }^{5}$ Department of Environmental and Occupational Health, Universiti Putra Malaysia, Selangor - 43400, Malaysia; \\ raihanah.chokeli@gmail.com, joshisyazani88@gmail.com
}

\begin{abstract}
The physiological differences between men and women have resulted in discrepancies of pesticides' toxicokinetic and toxicodynamic mechanism. It is speculated that women are more prone to exposure to pesticides than men, which increases the risks to their metabolic health. This study aims to establish a link between long-term, low-level exposure to pesticides and its potential adverse metabolic health risks in farming villages by using the parameters of body composition and acetylcholinesterase activity as indicators. The result indicates that the blood cholinesterase levels in males are proportionally lower than in females. The distinction of farmer and non-farmer as an occupation often shows a different degree of metabolic health symptoms unique to the sex. In addition, the sexual differences in the correlation of the level of blood cholinesterase with the body mass index, visceral muscle, body fat and visceral fat among the farming communities in the same farming village are of considerable interest. These findings provide a mechanistic explanation for women's vulnerability to pesticide exposure and indicate potential opportunities for early prevention and surveillance for these working women in the farming community.
\end{abstract}

Keywords: Acetylcholinesterase, Body Composition, Blood Pressure, Sex, Metabolic Health Risks

\section{Introduction}

The increased demand on the domestic and global markets is directly proportional to the country's annual pesticides imports. Since pests and plant diseases pose a major problem in agricultural production, a past survey conducted at our study location found it common for vegetable farmer's to use a variety of pesticides on their crops, including $53 \%$ of fungicides, $44 \%$ of insecticides and $3 \%$ of herbicides. Among the most hazardous pesticides used by vegetable farmers are of Lambda-cyhalothrin, Chlorpyrifos, Cypermethrin, Dicofol, Permethrin, Trichlorfon and Chlorfenapyr' ${ }^{1}$. In March 2015, traces of banned pesticides such as endosulfan, endrine ketone, alrine and DDT were found in the piped water and river. Most of these pesticides are environmentally persistent and have been related to chronic health effects such as developmental disorder, cancer, reproductive problem and a wide range of metabolic health conditions, e.g. diabetes, obesity and metabolic dysfunction.

Past studies among highland farming communities found that most reported having chronic health conditions. For instances, $\operatorname{Lim}(2016)^{2}$ found that among 138 respondents, $25.4 \%$ were overweight and $34.8 \%$ were obese; female mean body fat percentage (BFP) was higher than the BFP in males; and $8.2 \%$ farmers reported with hyperglycemia, $14.8 \%$ with systolic hypertension, and $11.5 \%$ with diastolic hypertension ${ }^{4}$. The physiological differences between men and women, such as body

${ }^{*}$ Author for correspondence 
weight, length, and surface area; total body water; and extracellular and intracellular water conditions, contribute, to differences in the mechanism of pesticides toxicokinetics ${ }^{5,6}$. Considering the physiological characteristics of women, we believe their unique lifestyle and activities may also increase their susceptibility to pesticides. Increasing numbers of studies have shown that high levels of endocrine disrupting (ED) and persistent organic pollutants (POPs) classes of pesticides, such as poly-chlorinated biphenyl (PCB) and dichlorodiphenyldichloroethylene (DDE) have been detected in fat specimens from women with breast cancer and in the maternal milk and blood samples, ${ }^{7,8}$. A recent animal model study further established the correlation between pesticides developmental exposure and the increased risks of developing metabolic syndrome in female mice and later in life of the female offspring 9 .

Another review of metabolic syndrome research conducted in Malaysia between the years 2000 and 2015 also suggested that metabolic syndrome is more prevalent among women than $\operatorname{men}^{10}$. When examining the geographical distribution of Malaysian population, there has been a higher prevalence of metabolic syndrome among men in urban areas and women in rural areas. There has also been steeper increase in the prevalence of metabolic syndrome with age among these women. Sadly, there are still significant disparities in women's participation in occupational health studies.

In this study, we hypothesized that the women from farming villages are more vulnerable to exposure to pesticide than men, thereby increasing the risk of their metabolic health. By using blood acetylcholinesterase level as the indicator of pesticide exposure, the objective of this study was to examine the sexual differences in metabolic health risks among villagers from pesticide-treated farming villages.

\section{Materials and Methods}

This cross-sectional comparative pilot study was carried out among a local farming community (adult population) that participates voluntarily. A total of 61 adults who meet the inclusion criteria have been recruited, including having spent at least 10 years in the farm village, having at least one family member working in the farmland, and residing about $10 \mathrm{~km}$ from the working farmland.

\subsection{Biomarker of Exposure (Blood Cholinesterase Level)}

Blood cholinesterase level monitoring is a useful tool for assessing potential pesticides exposure among the study population. A blood cholinesterase test kit (Lovibond, AF267; Tintometer Ltd., UK) was used in this study to monitor the pesticides with a few drops of blood at the fingertip. Based on the colorimetric principle of the colour indicator (bromothymol blue solution) used, each sample was analyzed on site as guided by the test kit; readings were collected after 4 to 5 minutes. The changes of color using the color indicator are to show the phosphorylation of the acetylcholinesterase enzyme (AChE) at the nerve endings from mixture of organophosphates (OPs) and carbamates (CBs) among the study population.

\subsection{Blood Pressure and Body Composition Monitoring}

Metabolic syndrome is a cluster of conditions-increased blood pressure, high blood sugar, excess body fat around the waist, and abnormal cholesterol or triglyceride levels. In this context, health risks associated with pesticides are evaluated by considering the body mass index (BMI), skeletal muscle mass, body fat mass, percentage of visceral fat and blood pressure as the clinical criteria of metabolic syndrome. In order to ensure the accuracy of this measurement, participants were restricted from taking the measurement after vigorous exercises or after drinking alcohol or a large amount of water.

A blood pressure monitor (Omron, Automatic Blood Pressure Monitor, and Model HEM-7320) was used to measure the blood pressure and pulse rate of our participants. This blood pressure monitor include a cuff, a pressure sensor which detects a pressure in the cuff, and a pressure regulating device which increases the pressure of the cuff, a pulse-amplitude determining device for determining an amplitude of each of pulses of a pulse wave which are produced in the cuff and detected by the pressure sensor while the cuff pressure is increased.

Body composition is the proportion of fat, muscle, and bone of an individual's body, expressed as the body fat mass and skeletal body mass. The bioelectrical impedance analysis (BIA) (Omron, Body Composition Monitor and scale, Model HBF-514) was used in this study to assess the fat-free mass and total body water in subjects with no apparent fluid and electrolyte abnormality. During the measurement of body composition, the participant was guided with correct posture during the measurement, i.e. step on the heel electrode with the weight evenly distributed on the measuring surface, while at the same time holding the grip electrodes tightly by raising the arms horizontally and the elbows straight to form a $90^{\circ}$ angle to their body. Once the measurement was completed, the BMI, percentage of skeletal muscle, the percentage of body fat (BFP), and visceral fat were recorded.

\section{Findings}

Table 1, summarizes the socio-demographical background and health status among the farming community by taking into account sex differences. A total of 36 women and 45 males from the farming community participated in this study, the average age of both is $42.86-48.12$ years and at least half of 
Table 1. The socio-demographical and health status background among farming community (sex-difference)

\begin{tabular}{|c|c|c|c|}
\hline \multirow[b]{2}{*}{ Variable } & \multirow[b]{2}{*}{ Category } & \multicolumn{2}{|c|}{$\begin{array}{c}\text { Frequency } \\
\text { (Percentage) }\end{array}$} \\
\hline & & $\begin{array}{c}\text { Female } \\
(n=26)\end{array}$ & $\begin{array}{c}\text { Male } \\
(n=35)\end{array}$ \\
\hline \multirow[t]{5}{*}{ Age } & $18-29$ years & $3(11.5)$ & $6(17.1)$ \\
\hline & $30-39$ years & $2(7.7)$ & $10(28.6)$ \\
\hline & $40-49$ years & $8(30.8)$ & $7(20.0)$ \\
\hline & $50-59$ years & $8(30.8)$ & $7(20.0)$ \\
\hline & 60 years and above & $5(19.2)$ & $5(14.3)$ \\
\hline \multirow[t]{3}{*}{ Marital Status } & Single & $2(7.7)$ & $8(22.9)$ \\
\hline & Married & $22(84.6)$ & $23(65.7)$ \\
\hline & Divorced/widow & $2(7.7)$ & $4(11.4)$ \\
\hline \multirow[t]{3}{*}{ Educational Level } & Never to school & $2(7.7)$ & $2(5.7)$ \\
\hline & Elementary school & $12(46.2)$ & $11(31.4)$ \\
\hline & High school \& above & $12(46.2)$ & $22(62.9)$ \\
\hline $\begin{array}{l}\text { Working as farmer } \\
\text { or in the farming } \\
\text { industry }\end{array}$ & $\begin{array}{l}\text { Yes } \\
\text { No }\end{array}$ & $\begin{array}{l}14(53.8) \\
12(46.2)\end{array}$ & $\begin{array}{l}20(57.1) \\
15(42.9)\end{array}$ \\
\hline \multirow{2}{*}{$\begin{array}{l}\text { Self-reported } \\
\text { metabolic disease }\end{array}$} & Yes & $4(15.4)$ & $8(22.9)$ \\
\hline & No & $22(84.6)$ & $27(77.1)$ \\
\hline \multirow{2}{*}{$\begin{array}{l}\text { History of } \\
\text { acute pesticide } \\
\text { poisoning }\end{array}$} & Yes & $6(23.1)$ & $6(17.1)$ \\
\hline & No & $20(76.9)$ & $29(82.9)$ \\
\hline
\end{tabular}

the respondents claiming to be working as farmers in this highland farming sector. Nevertheless, only a few respondents self-reported to have chronic metabolic diseases and have had any history of acute pesticide poisoning.

Next, different parameters were assessed to determine the health status of the study population, such that, "BMI" is the number calculated from the weight and height of an individual, which is considered to be a reliable indicator of human body fatness, "skeletal muscle percentage" is the muscle mass that acts as a motor in the intake of body energy, "body fat" plays a vital role in storing energy and protecting internal organs, and "visceral fat" is found in the abdomen and surrounding vital organs. In addition, the level of blood cholinesterase is used to indicate the depression of cholinesterase among farm villagers from their chronic and low exposure to pesticides. Since the distribution of body fat in men and women is different, the classification of body fat and the percentage of skeletal muscle is different between the genders to compare the parameters of blood cholinesterase and metabolic health among the farmers.

Result in (Table 2) indicated that males showed proportionally greater changes in blood cholinesterase levels compared to females, with both levels of blood cholinesterase suggesting relatively low levels of acetylcholine based on the colorimetric measurements for the rapid field sampling among them. All men and women in this study reported to have normal BMI. However, women generally have lower percentage of the skeletal muscle and relatively higher body and visceral fat compared with men. Overall, there was a higher prevalence rate of abdominal obesity among women and a higher prevalence rate of hypertension among men.

Table 2. Comparison of blood cholinesterase and metabolic health indicators among farming community

\begin{tabular}{|c|c|c|c|c|}
\hline & \multicolumn{2}{|c|}{ Mean (SD) } & \multirow{2}{*}{ p-value } \\
\hline & & Female $(n=26)$ & Male $(n=35)$ & \\
\hline \multicolumn{2}{|c|}{$\begin{array}{l}\text { Body Mass Index } \\
(\mathrm{BMI})\left(\mathrm{kg} / \mathrm{m}^{2}\right)\end{array}$} & $24.20(3.49)$ & $24.96(4.07)$ & 0.346 \\
\hline \multicolumn{2}{|c|}{$\begin{array}{l}\text { Skeletal Muscle } \\
\text { Mass (\%) }\end{array}$} & $29.08(4.53)$ & $37.69(4.45)$ & $<0.001^{* *}$ \\
\hline \multicolumn{2}{|c|}{ Body Fat Mass (\%) } & $32.01(7.94)$ & 20.98 (7.98) & $<0.001^{\star *}$ \\
\hline \multicolumn{2}{|c|}{ Visceral Fat (\%) } & $6.04(2.22)$ & $8.23(4.44)$ & $0.024^{*}$ \\
\hline \multirow{2}{*}{$\begin{array}{l}\text { Blood } \\
\text { Pressure } \\
(\mathrm{mmHg})\end{array}$} & Systolic & $127.74(16.73)$ & $133.77(13.63)$ & 0.126 \\
\hline & Diastolic & $79.53(9.38)$ & $82.86(11.02)$ & 0.221 \\
\hline \multicolumn{2}{|c|}{ Pulse Rate (bpm) } & 76.96 (8.29) & $74.37(10.14)$ & $0.029^{*}$ \\
\hline \multicolumn{2}{|c|}{$\begin{array}{l}\text { Blood Cholinesterase } \\
\text { Level (AChE) (\%) }\end{array}$} & $53.01(20.71)$ & $49.23(23.70)$ & 0.519 \\
\hline
\end{tabular}

** p-value is significant at 0.01 levels; ${ }^{*} \mathrm{p}$-value is significant at 0.05 levels

Table 3. The association between blood cholinesterase and metabolic health parameters among females in community

\begin{tabular}{|l|c|c|c|}
\hline \multirow{2}{*}{ Variable } & \multicolumn{3}{|c|}{${ }^{\mathrm{a}}$ Blood Cholinesterase Level, AChE } \\
\cline { 2 - 4 } & $\begin{array}{c}\text { Farmer, } \\
\mathbf{n}=14\end{array}$ & $\begin{array}{c}\text { Non-farmer, } \\
\mathbf{n}=\mathbf{1 2}\end{array}$ & Total, $\mathbf{n}=26$ \\
\hline $\begin{array}{l}\text { Body Mass } \\
\text { Index (BMI) }\end{array}$ & $\begin{array}{c}-0.465 \\
(0.128)\end{array}$ & $-0.329(0.251)$ & $-0.593(0.001)^{* *}$ \\
\hline $\begin{array}{l}\text { Skeletal Muscle } \\
\text { Mass (\%) }\end{array}$ & $\begin{array}{c}0.621 \\
(0.031)^{*}\end{array}$ & $0.082(0.780)$ & $0.262(0.195)$ \\
\hline $\begin{array}{l}\text { Body Fat Mass } \\
\text { (\%) }\end{array}$ & $\begin{array}{c}-0.588 \\
(0.044)^{*}\end{array}$ & $-0.141(0.332)$ & $-0.374(0.048)^{*}$ \\
\hline $\begin{array}{l}\text { Visceral Fat } \\
\text { (\%) }\end{array}$ & $\begin{array}{c}-0.463 \\
(0.129)\end{array}$ & $-0.252(0.384)$ & $-0.406(0.039)^{*}$ \\
\hline $\begin{array}{l}\text { Blood Pressure } \\
\text { (Systolic) }\end{array}$ & $\begin{array}{c}-0.751 \\
(0.005)^{* *}\end{array}$ & $-0.458(0.632)$ & $-0.180(0.380)$ \\
\hline $\begin{array}{l}\text { Blood Pressure } \\
\text { (Diastolic) }\end{array}$ & $\begin{array}{c}-0.533 \\
(0.074)\end{array}$ & $-0.681(0.007)^{* *}$ & $-0.162(0.429)$ \\
\hline Pulse Rate & $\begin{array}{c}-0.062 \\
(0.849)\end{array}$ & $0.153(0.603)$ & $-0.106(0.605)$ \\
\hline
\end{tabular}

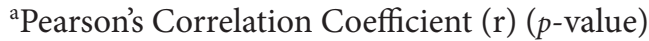

${ }^{* *} \mathrm{p}$-value is significant at 0.01 levels; ${ }^{*} \mathrm{p}$-value is significant at 0.05 levels 
Table 4. The association between blood cholinesterase and metabolic health parameters among males in highland farming community $(\mathrm{N}=35)$

\begin{tabular}{|l|c|c|c|}
\hline \multirow{2}{*}{ Variable } & \multicolumn{3}{|c|}{${ }^{\mathrm{a}}$ Blood Cholinesterase Level, AChE } \\
\cline { 2 - 4 } & $\begin{array}{c}\text { Farmer, } \\
\mathbf{n}=\mathbf{2 0}\end{array}$ & $\begin{array}{c}\text { Non-farmer, } \\
\mathbf{n}=\mathbf{1 5}\end{array}$ & $\begin{array}{c}\text { Total, } \\
\mathbf{n}=35\end{array}$ \\
\hline $\begin{array}{l}\text { Body Mass } \\
\text { Index (BMI) }\end{array}$ & $\begin{array}{c}-0.698 \\
(0.004)^{* *}\end{array}$ & $-0.163(0.491)$ & $-0.385(0.022)^{*}$ \\
\hline $\begin{array}{l}\text { Skeletal Muscle } \\
\text { Mass (\%) }\end{array}$ & $\begin{array}{c}0.607 \\
(0.016)^{*}\end{array}$ & $0.476(0.034)$ & $0.211(0.224)$ \\
\hline $\begin{array}{l}\text { Body Fat Mass } \\
\text { (\%) }\end{array}$ & $\begin{array}{c}-0.681 \\
(0.005)^{* *}\end{array}$ & $-0.387(0.092)$ & $-0.248(0.151)$ \\
\hline $\begin{array}{l}\text { Visceral Fat } \\
\text { (\%) }\end{array}$ & $\begin{array}{c}-0.641 \\
(0.010)^{* *}\end{array}$ & $-0.080(0.739)$ & $-0.392(0.020)^{*}$ \\
\hline $\begin{array}{l}\text { Blood Pressure } \\
\text { (Systolic) }\end{array}$ & $\begin{array}{c}-0.256 \\
(0.357)\end{array}$ & $-0.280(0.232)$ & $-0.089(0.611)$ \\
\hline $\begin{array}{l}\text { Blood Pressure } \\
\text { (Diastolic) }\end{array}$ & $\begin{array}{c}-0.245 \\
(0.380)\end{array}$ & $-0.156(0.512)$ & $-0.083(0.637)$ \\
\hline $\begin{array}{l}\text { Pulse Rate } \\
\text { (bpm) }\end{array}$ & $\begin{array}{c}0.296 \\
(0.284)\end{array}$ & $0.078(0.744)$ & $0.032(0.853)$ \\
\hline
\end{tabular}

${ }^{a}$ Pearson's Correlation Coefficient (r) ( $p$-value)

${ }^{* *} \mathrm{p}$-value is significant at 0.01 levels; ${ }^{*} \mathrm{p}$-value is significant at 0.05 levels

The association between the metabolic health parameters and blood cholinesterase among the study population are discussed as in Table 3 and Table 4. According to Table 3, female farmers in the farming community show significant negative correlations of blood cholinesterase levels with body fat, and blood pressure (systolic), but a positive correlations with the percentage of skeletal muscle. Overall female farming community shows a significant negative correlations of blood cholinesterase levels and BMI, percentage of body and visceral fat.

On the other hand, Table 4 summarizes that male farmers in the farming community show significant negative correlations of blood cholinesterase levels with BMI, percentage of body fat and visceral fat, but a significant positive correlation with their percentage of skeletal muscle. Overall male farming community exhibits significant negative correlation of blood cholinesterase levels, with BMI, and the percentage of visceral fat.

\section{Discussion}

Past research mainly focuses on investigating the occupational health effects of pesticide exposure among male farmers, in

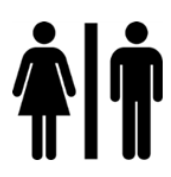

Sex Different (Toxicokinetics)

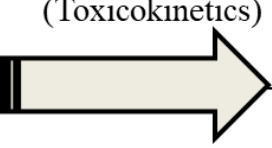

- Women have higher percent body fat, and relatively more adipose tissue than men

- Women has low basal metabolic rate $(\mathrm{BMR})$ than men

- Volume of distribution among women is smaller

- Toxics clearance from women body is slower

(Soldin and Mattison 2013)

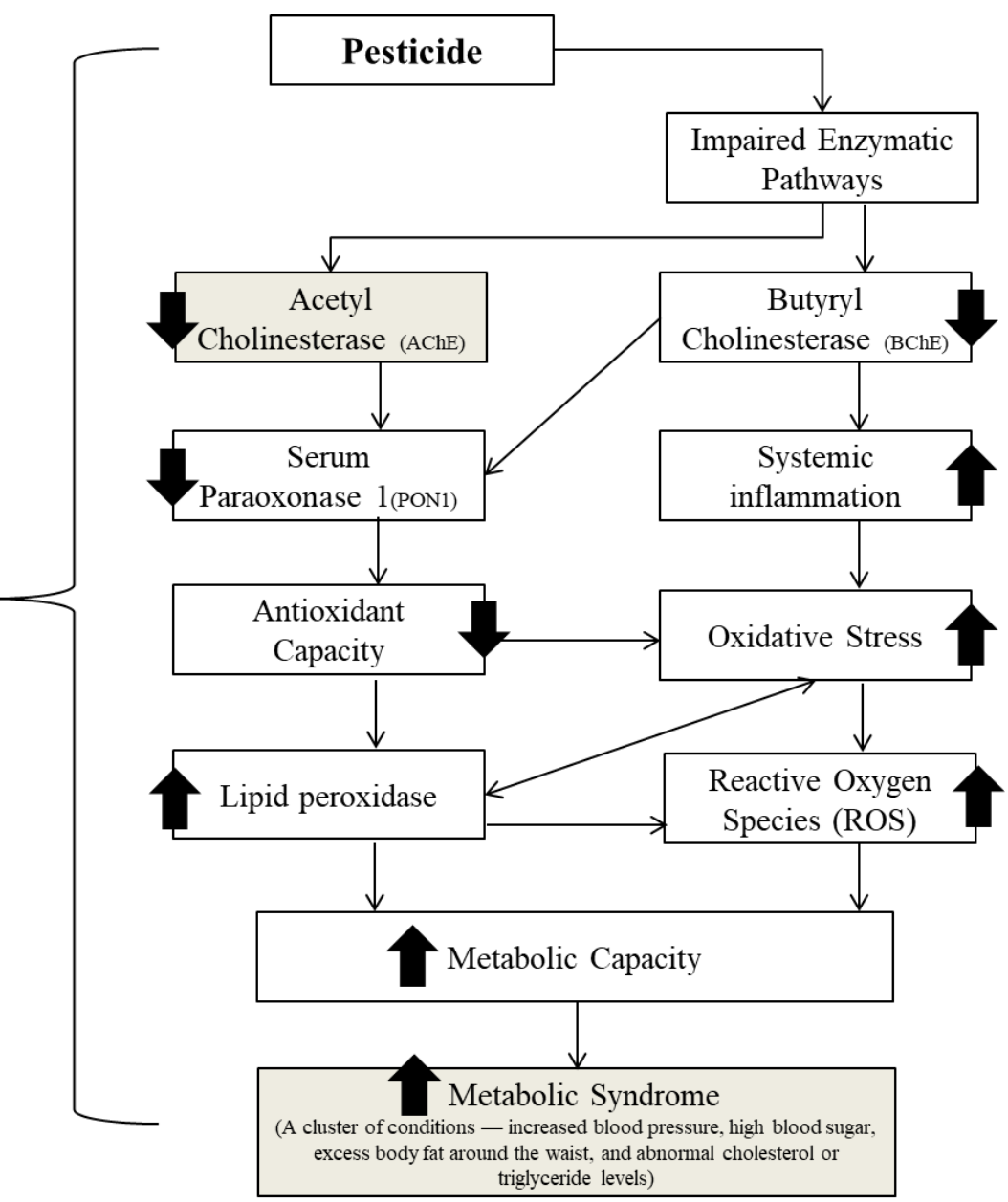

Figure 1. Conceptual scheme to understand the sexual-differences in the mechanism of pesticides and metabolic-related health risk suggested in this study. 
reality there is still limited evidence of the potential effects on occupational health among female farmers. In addition, the accumulative effects of the pesticide's residuals in the environments on the women living in the vicinity of the farming village are also rarely highlighted. Since rural women have a higher prevalence rate of metabolic syndrome than men ${ }^{10,11}$ this study aimed to examine the sexual disparity in determining the metabolic health risks associated with pesticides and outlining possible context mechanisms of the relationship between pesticides and metabolic syndrome among the highland farming community. On the basis of the result tabled earlier, (Figure 1) describes the empirical mechanism of potential metabolic syndrome from exposure to pesticides in the farming community at long-term and low levels exposure.

\subsection{Sexual Differences in Human Physiology}

Table 2 reveals that females are genetically engineered to bear more on their bodies than males. A healthy and active woman's body fat percentage is 18 -20 percent, whereas for men this estimate is $10-15$ percent. On the other hand, males have more skeletal muscle mass and lean muscle mass compared to women. The skeletal muscles of men are stronger and make maximum output compared to women's skeletal muscles ${ }^{12}$.

The postulate the conceptual scheme of the (possible) mechanism of metabolic health outcome by associating the levels of blood cholinesterase and other metabolic health risks among the farming community according to the results obtained in (Tables 3 and 4). This is achieved by hypothesizing that agricultural populations from their highland farming villages are exposed to long-term and low levels of the mixture of pesticides. (mainly OP used in farming villages).

\subsection{Pesticides and Enzymatic pathways}

Organophosphate and carbamate function as inhibitors of AChE that affects many organs, including the peripheral and central nervous systems, muscles, liver, pancreas, and brain $^{13,14}$. With this ability to inhibit AChE, on the other hand, Paraoxonase 1 (PON1) enzyme can detoxify OP and CB by hydrolyzing its metabolites. Most studies found that low serum in the PON1 group had higher inhibition of cholinesterase to detoxify the activated $\mathrm{OP}^{15}$. PON1 is an enzyme expressed in the liver and excreted in the blood where it prevents low-density lipoprotein (LDL) oxidation by inhibiting the accumulation of lipid peroxides, a precursor of oxidative stress ${ }^{16,17}$. Its ability to detoxify the oxon-derivatives of the activated OP and CB pesticides, however, have lowered their antioxidant capacity levels, while increasing the oxidation of LDL and enhancing the free radical induced lipid peroxidation process.
Oxidation of LDL is a crucial mechanism in the pathophysiology of atherosclerosis and in the development of cardiovascular diseases under normal circumstances. In other words, the effects of PON1 in inhibiting in vitro LDL oxidation have indicated that PON1 may play a protective role in the onset of cardiovascular disease $e^{12,18}$. The low PON1 enzyme found among farmers, on the other hand, suggested that OP insecticides are hydrolyzed ${ }^{18,19}$. The person with low PON1 activity due to exposure to pesticides now accumulates lipid peroxides in the $\mathrm{LDL}^{20}$. Low PON1 activity in the reduced metabolic capacity during the detoxifying process, and thus further increased susceptibility among farmers to OP toxicity. Consequently, low PON1 levels due to the pesticide toxicity mechanism have decreased both the lipid metabolism in the body and the metabolic capacity.

\subsection{Pesticide and Lipid Solubility}

Lipophilic types of pesticides, e.g. Organochlorine (OC), OP, $\mathrm{CB}$, and some other ED pesticide are known sfor their lipid solubility and metabolism resistance. For exmaple, serum concentrations of p,p'-DDE o,p'-DDD, and endosulfan -I, -sulfate, -lactone, and -diol have been to be significantly correlated with their concentrations of adipose tissues ${ }^{12}$; Chlorpyrifos and diazinon are lipophilic, so that the compound that divides into body fat can be eliminated slowly ${ }^{13}$. In addition, $\mathrm{OP}$ and $\mathrm{CB}$ may disrupt the enzymatic pathways involved in the metabolism of carbohydrates, fats, and protein in the cytoplasm, mitochondria, and peroxisomes. It is believed that OP and CB show this effect by inhibiting AChE or directly affecting target organs. They also influence themetabolism of the lipids in the adipose tissues and alter the glucose pathway in other cells. Other studies have also shown that enzymatic activity of butyrylcholinesterase (BChE) is increased in a number of conditions associated with metabolic syndrome, including obesity, diabetes, and cardiovascular disease ${ }^{14,15}$. As a common mechanism, all $\mathrm{OP}, \mathrm{CB}$, and $\mathrm{OC}$ cause cellular oxidative stress by influencing mitochondrial function and therefore disrupt the body's neuronal and hormonal status ${ }^{16}$.

\subsection{AChE and Pesticide-related Metabolic Health Risks}

$\mathrm{AChE}$ is a useful biomarker as it provides an integrated measurement of the overall bioavailable contaminants including other environmental and occupational pesticides exposure, including OP and CB. Nonetheless, there is limited research available to compare the relationship between $\mathrm{AChE}$ and the potential risks to metabolic health associated with pesticides. Considering the disparity in physiology and toxicokinetics between female and male, this study suggests that the effect of metabolic health risks associated with 
pesticides can be monitored to predict the potential pesticide toxicity levels in the human body. In this regard, our hypothesis is supported by a recent study which found that BChE is strongly affects fat metabolism, and has a significant impact on fat accumulation ${ }^{21}$, and several other studies have shown that the BChE's enzymatic activity is increased in several metabolic syndrome-related conditions, including obesity, diabetes, and cardiovascular diseases ${ }^{22,23}$.

While male show a higher level of pesticide toxicity compared to females in their blood cholinesterase level, the level of blood cholinesterase level among females in our study shows a great interest in BMI, skeletal muscle percentage, body fat and visceral fat. In contrast, the toxicity effects of pesticides among our men participants only show subtle effects on their body composition and blood pressure level. Such results provide a mechanistic explanation for women's vulnerability to exposure to pesticides and indicate a possible window of opportunity for early prevention and monitoring (of metabolic symptoms associated with pesticides) for these working women in the farming community.

\subsection{Women as the vulnerable group}

The metabolism of chemicals can be estimated by basal metabolic rates (BMR). Since men and women have different physiology for toxicodynamics and toxicokinetics, on average, men have an average BMR higher than women. As shown in this study, women generally have a higher body and visceral fat and men have higher skeletal muscle mass. The difference in metabolism of adipose tissue from that of muscle tissue between different sexes was attributed to the metabolism of adipose tissue in the body. In fact, other studies also argued that the lower BMR per unit body surface area among women reflects a decrease in lean body mass due to a smaller skeletal muscle component ${ }^{5}$. For instance, lipophilic pesticides compounds tend to spread to tissue and fat where there is a longer duration of toxicokinetics action happened due to their large volumes of adipose tissues than males. Experimental of other animals also found that DDT reduced the ability of female mice to generate heat. Instead of burning calories, these female mice are storing fats in their body causing them has the higher risk of obesity, type 2 diabetes, and cholesterol ${ }^{9}$.

\section{Conclusion}

Since the assessment of body composition is important to identify those with clinical parameters of metabolic syndrome, it may be used to provide guidance to occupational health practitioners or emergency physicians in predicting early health risk management, as well as clinical course of acute or chronic pesticide, particularly among women working farmers or women living in the farming village. On the basis of the current knowledge of the pesticide mechanism and metabolic syndrome, we proposed that relevant epidemiological studies should be conducted to investigate the exact relationship between the levels of exposure to these pesticides and the incidence of metabolic disorders among the farming community.

\section{Research Ethics}

Research ethics were approved for this study was approved by (Ethics Committee for Research Involving Human Subjects Universiti Putra Malaysia). This cross-sectional pilot study was carried out on 60 villagers living in agricultural villages after they had returned their written informed consent.

\section{Conflict of Interest Statement}

The authors declare no conflict of interest.

\section{Funding}

This research is funded by the International Science Council under AI-SOCD Seed Grant Programme 2018.

\section{References}

1. Mispan MR, Haron SH, Ismail BS, Abd Rahman NF, Khalid $\mathrm{K}$, Abdul Rasid MZ. The use of pesticides in agriculture area, cameron highlands. International Journal of Scientific Progress and Research. 2015; 15(1): 19-22.

2. Lim KG. A review of adult obesity research in Malaysia. Medical Journal of Malaysia. 2016; 71(1): 1-19.

3. Azuwani AR, Noor Khairiah K, Cheong YZ, Kok CC, Aw NSL, Nadiah MS, Abdul Rashid K. Body fat percentage distribution of an orang asli group (Aborigines) in cameron highlands, Malaysia. Malaysia Journal of Nutrition. 2013; 19(2): 205-14.

4. Abdul Hamid Z, Harun Z, Lubis SH, Mohamed N, Ishak I, Othman $\mathrm{HF}$, et al. Adoption of the mobile health screening programme for farming communities: A study among pesticide-exposed farmers from North East of Peninsular Malaysia. Malaysian Journal of Health Sciences. 2014. DOI: 10.17576/jskm-2014-1202-09. https://doi.org/10.17576/JSKM-2014-1202-09.

5. Soldin OP, Mattison DR. Sex differences in pharmacokinetics and pharmacodynamics. Clin Pharmacokinet. 2013; 48(3): 143-57. https://doi.org/10.2165/00003088-200948030-00001. PMid:19385708 PMCid:PMC3644551.

6. Ngowi AV, Maeda DN, Partanen TJ. Assessment of the ability of health care providers to treat and prevent adverse health effects of pesticides in agricultural areas of Tanzania. Int. J. Occup. Med .Environ. Health. 2001; 14(4): 349-56.

7. Mnif W, Hassine AIH, et al. Effect of endocrine disruptor pesticides: A review. Int. J. Environ. Res. Public Health. 2011; 8(6): 2265-303. https://doi.org/10.3390/ijerph8062265 .PMid:21776230, PMCid:PMC3138025. 
8. Qu W, Suri RPS, Bi X, Sheng G, Fu J. Exposure of young mothers and newborns to OrganoChlorine Pesticides (OCPs) in Guangzhou; China. Sci. Total Environ. 2010; 408: 3133-38. https://doi.org/10.1016/j.scitotenv.2010.04.023. PMid:20471063.

9. Michele LM, Emma K, Erin M, Claudia L, Michael R. La F, John WN, Christoph B. Perinatal exposure of mice to the pesticide DDT impairs energy expenditure and metabolism in adult female offspring. PLoS ONE. 2014. DOI: 10.1371/journal.pone.0103337. https://doi.org/10.1371/journal.pone.0103337. PMid:25076055, PMCid:PMC4116186.

10. Lim KG, Cheah WK. A review of metabolic syndrome research in Malaysia. Med. J. Malaysia. 2016; 71(1): 20-28.

11. Botella B, Crespo J, Rivas A, et al. Exposure of women to organochlorine pesticides in Southern Spain. Environmental Research. 2004; 96(1): 34-40. https://doi.org/10.1016/j. envres.2003.10.001. PMid:15261782.

12. Janssen I, Steven BH, Wang ZM, Ross R. Skeletal muscle mass and distribution in 468 men and women aged 18-88 year old. J. Appl. Physiol. 2000; 89(1): 81-88. https://doi.org/10.1152/ jappl.2000.89.1.81. PMid:10904038.

13. Eaton DL, et al. Review of the toxicology of chlorpyrifos with an emphasis on human exposure and neurodevelopment. Crit. Rev. Toxicol. 2008; 38 (Suppl 2): 1-125. https://doi.org/10.1080/ 10408440802272158. PMid:18726789.

14. Inacio Lunkes G, Stefanello F, Sausen Lunkes D, Maria Morsch V, Schetinger MR, Goncalves JF. Serum cholinesterase activity in diabetes and associated pathologies. Diabetes Res. Clin. Pract. 2006; 72(1): 28-32. https://doi.org/10.1016/j.diabres.2005.08.009. PMid:16233931.

15. Alcantara VM, Oliveira LC, Rea RR, Suplicy HL, Chautard-FreireMaia EA. Butyrylcholinesterase activity and metabolic syndrome in obese patients. Clin. Chem. Lab. Med. 2005; 43(3): 285-88. https://doi.org/10.1515/CCLM.2005.048. PMid:15843232.

16. Karami-Mohajeri S, Abdollahi M. Toxic influence of organophosphate, carbamate, and organochlorine pesticides on cellular metabolism of lipids, proteins, and carbohydrates: A systematic review. Hum. Exp. Toxicol. 2010; 30(9): 1119-40. https://doi.org/10.1177/0960327110388959. PMid:21071550.

17. Richard SA, Frank EA, D’Souza CJM. Correlation between cholinesterase and paraoxonase 1 activities: Case series of pesticide poisoning subjects. Bioimpacts. 2013; 3(3): 119-22.

18. Himbergen TM, Tits LJH, Roest M, Stalenhoef AFH. The Story of PON1: How an organophosphate hydrolyzing enzyme is becoming a player in cardiovascular medicine. The Journal of Medicine. 2006; 64(2): 34-38.

19. Huen K, Harley K, Brooks J, et al. Development changes in PON1 enzyme activity in young children and effects of PON1 polymorphisms. Environmental Health Perspective. 2009; 117(10): 1632-38. https://doi.org/10.1289/ehp.0900870. PMid: 20019917 PMCid: PMC2790521.

20. Cost LG, Cole TB, Furlong CE. Polymorphisms of Paraoxonase (PON1) and their significance in clinical toxicology of organophosphates. J. Toxicol.Clin. Toxicol.2003;41(1).https://doi .org/10.1081/CLT-120018269. PMid:12645966.

21. Vicky PC, Gao Y, Geng L, Stout MB. Butyrylcholinesterase deficiency promotes adipose tissue growth and hepatic lipid accumulation in male mice on high-fat diet. Endocrinology. 2016; 157(8): 3086-95. https://doi.org/10.1210/en.2016-1166. PMid:27300766, PMCid: PMC4967128.

22. Iwasaki $T$, Yoneda $M$, Nakajima A, Terauchi Y. Serum butyrylcholinesterase is strongly associated with adiposity, the serum lipid profile and insulin resistance. Intern. Med. 2007; 46(19): 1633-39. https://doi.org/10.2169/ internalmedicine.46.0049. PMid:17917325.

23. Inacio Lunkes G, Stefanello F, Sausen Lunkes D, Maria Morsch V, Schetinger MR, Goncalves JF. Serum cholinesterase activity in diabetes and associated pathologies. Diabetes Res. Clin. Pract. 2006; 72(1): 28-32. https://doi.org/10.1016/j.diabres.2005.08.009 .PMid:16233931. 